\title{
Mechanisms and Effectiveness of Imagery Strategies in Reducing Disgust in Contamination-Related Obsessive-Compulsive Disorder: Comparing Imagery Rescripting, Imagery Self-compassion and Mood-Focused Imagery
}

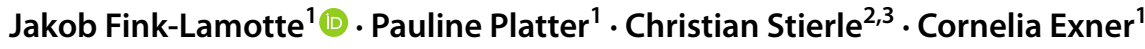

Accepted: 31 October 2021 / Published online: 12 November 2021

(c) The Author(s) 2021

\begin{abstract}
Background Strong feelings of disgust and anxiety are maintaining factors in contamination-related obsessive-compulsive disorder (C-OCD). To this day there are not many studies that investigated strategies for changing pathological disgust. In a previous study, it was shown that imagery rescripting could successfully change disgust. However, whether imagery rescripting or more general imagery processing, helps to reduce pathological disgust, remains unclear. Therefore, the aim of the present study was to investigate how successful imagery rescripting is in comparison to imagery self-compassion and a passive positive imagery condition in reducing disgust.

Methods For this, the three strategies were compared to each other on 2 days (within-subject) in a laboratory experiment. The study included 24 subjects with diagnosed C-OCD, and 24 matched, healthy controls (between-subject).

Results The results show that all three strategies changed disgust, they do not differ from each other and that different traits appear to influence the strategies' success or failure. The theoretically derived underlying mechanisms of the strategies were found in an elaborate content analysis.

Conclusions The present study provides first indications that imagery in general can help to change pathological disgust experience.
\end{abstract}

Keywords Disgust $\cdot$ Imagery $\cdot$ Contamination $\cdot$ Obsessive-compulsive disorder $\cdot$ Compassion

\section{Introduction}

Disgust and fear are important maintaining factors in the contamination-related subtype of obsessive-compulsive disorders (C-OCD, Cisler et al., 2009), yet studies have shown that people with $\mathrm{C}$-OCD have greater difficulty in changing disgust compared to fear reactions (Armstrong \& Olatunji, 2017; McKay, 2006). Nevertheless, exposure therapy with response prevention is a very effective therapy for changing

Jakob Fink-Lamotte

jakob.fink@uni-leipzig.de

1 Clinical Psychology and Psychotherapy, University of Leipzig, Neumarkt, 9-19, 04081 Leipzig, Germany

2 IUBH Internationale Hochschule, Zenostraße 6, 83435 Bad Reichenhall, Germany

3 Schön-Klinik Bad Bramstedt, Birkenweg 10, 24576 Bad Bramstedt, Germany
OCD symptoms (Öst et al., 2015), and a recent study has shown that disgust and fear habituated equally quickly when longer exposure sessions were conducted (Mathes et al., 2020). Although directly changing disgust should be a central aspect of a successful treatment of C-OCD (Knowles et al., 2018), there are only a few studies that have specifically investigated strategies which target disgust directly (Olatunji et al., 2017a, 2017b). In former studies, it was found that imagery rescripting ( $\mathrm{ImR})$ and cognitive reappraisal reduced disgust in people with C-OCD more effectively than a distraction-related control condition (Fink \& Exner, 2019; Fink et al., 2018). The results provide motivation for further investigation of imagery strategies to change pathological disgust more successfully.

In these studies, ImR was applied with the aim of changing the affective meaning of aversive memories and intrusive mental images (Wild et al., 2008) by changing the content of a negative image into a positive image (Holmes et al., 2007). 
The study by Fink et al. (2018) was criticized because it lacked an active and a passive imaginative control condition. If imagery is strongly associated with emotional reactivity, it may be that activating mental images is an adequate emotion regulation strategy. This reveals a gap in research, in that it is unclear whether ImR or simply imagery processing, is effective for reducing the disgust experienced. Therefore, in this study, the same (active) ImR condition was tested against an instruction to induce a positive mood state via imagery as a passive control (passive positive imagery condition). Hereby, people were instructed to think about their favorite hobby.

A strategy that might lie between passive imagination and active imagery would be a strategy in which the person is guided to work on more global aspects of the self (e.g., selfcompassion). In view of the fact that the emotional experience of obsessive-compulsive disorder is accompanied by fear, disgust, restlessness and tension, Paul Gilbert's compassion-focused therapy (CFT) can offer a helpful approach. Care and greater compassion for ourselves are associated with less stress, less anxiety and less depression (MacBeth \& Gumley, 2012), and promote resilience and more satisfied relationships (Neff \& Germer, 2013). A growing number of experimental studies have shown that CFT leads to a significant improvement in well-being and complements classical behavioural therapy methods (Eichholz et al., 2020; Sommers-Spijkerman et al., 2018). Therefore, as third strategy, a imagery self-compassion strategy was included in this experiment. To test whether imagery is more likely to help broader disgust experience or specific OCD-related disgust experience, a healthy control group was assessed.

A further aim of the present study was to test, whether assumed mechanisms underlying CFT and ImR are reported to be helpful during emotion regulation. According to Neff's theory of self-compassion (Neff, 2003), the central mechanisms of successful CFT is Self-Kindness (understanding, warmth, kindness, friendliness, inner strength and appreciation), Common Humanity (empathy, compassion (for others), the feeling of connectedness and community), and Mindfulness (acceptance, mindfulness and non-judgmental observation, calmness and taking perspective). Many of the qualities comprised in these categories, such as kindness and empathy, are also described by Gilbert (2009) as being central to compassion focused therapy. On the other hand, according to Holmes et al. (2007), it can be assumed that central mechanisms of ImR are the modification of the content of a negative image into a positive image (activating the imagination and using it as a tool), and second, the creation of a new positive image to rewrite negative schematic beliefs (activating the experience of a positive image). It can be assumed that ImR can cause a change in the image's meaning, which in turn changes the associated emotions. Therefore, a qualitative content analysis was carried out to answer the question of whether assumed mechanisms of action underlying the CFT and ImR strategies were reported and perceived as subjectively helpful, in terms of disgust regulation.

The aim of the present study is to investigate to what extent non-pathological and pathological disgusting experiences can be reduced by different interventions using imagery. We expect that as ImR is the most active strategy, it will reduce disgust most directly and therefore more effectively, than the more indirect CFT condition (1.1). We also expect that the passive positive imagery condition will be the least effective strategy (1.2). We expect that the clinical sample will benefit more from all active strategies than the healthy controls (2). We expect that people who have a stronger tendency to apply self-compassion will benefit more from the CFT condition (3.1), while the habitual use of imagery should be a general, positive predictor for all interventions using imagery (3.2). Furthermore, we expect that, in the content analysis, the participants will report the mechanisms of action that provide the theoretical bases of the respective strategies (4).

\section{Materials and Methods}

\section{Participants}

Forty-eight subjects volunteered to participate in this study. All the participants were native German speakers. The healthy control group participants were screened by telephone before being invited to the first appointment, to ensure that they matched the inclusion criteria. The participants had to be aged between 18 and 65 years old and have no history of or be currently diagnosed with, neurological disorders, traumatic brain injury, tic disorder, psychotic or bipolar disorder, substance abuse, or dependence. All the healthy control participants were paid $9.50 € / \mathrm{h}$ for participating in the experiment.

\section{Participants with the Washing Subtype of Obsessive- Compulsive Disorder}

Twenty-four participants, who met the Diagnostic and Statistical Manual of Mental Disorders (DSM-5; American Psychiatric Association, 2013) criteria for current OCD, were included in this experiment. All the OCD participants reported predominant symptoms of fear of contamination, washing and cleaning in the Yale-Brown Obsessive-Compulsive Scale (Y-BOCS; Goodman et al., 1989) checklist, and thus met the criteria for the contamination-related subtype of OCD (C-OCD). The participants in the clinical population were recruited from the Schön-Klinik Bad Bramstedt $(n=14)$, the outpatient' clinic of the University 
Table 1 Demographics and clinical characteristics by group

\begin{tabular}{|c|c|c|c|c|c|c|c|c|}
\hline \multirow[t]{2}{*}{ Demographic data } & \multicolumn{2}{|c|}{ C-OCD $(n=24)$} & \multicolumn{2}{|l|}{$\mathrm{HC}(n=24)$} & \multicolumn{4}{|c|}{ Statistical analysis } \\
\hline & Mean & S.D & Mean & S.D & $t$ & $d f$ & $P$ value & $d$ \\
\hline Age (years) & 33.79 & 13.11 & 33.79 & 13.40 & 0 & 46 & 1 & 0 \\
\hline Gender [men: women (\%men)] & $20: 4(17 \%)$ & & $20: 4(17 \%)$ & & $\chi^{2}(1)=0$ & & 1 & 0 \\
\hline Educational level $^{\text {a }}$ & 1.833 & 1.239 & 1.833 & 1.239 & 0 & 45.9 & 1 & 0 \\
\hline Session difference (days) & 7.818 & 4.393 & 8.250 & 9.023 & -0.203 & 44 & $.840^{\mathrm{b}}$ & -.060 \\
\hline \multicolumn{9}{|l|}{ Clinical data } \\
\hline Y-BOCS total (points) & 23.417 & 7.058 & - & - & - & - & - & \\
\hline Disgust propensity (FEE) & 97.875 & 21.559 & 75.292 & 22.718 & 3.532 & 46 & $<.001$ & 1.020 \\
\hline Anxiety (STAI-T) & 51.875 & 6.375 & 43.375 & 5.420 & 4.977 & 46 & $<.001$ & 1.437 \\
\hline Depression (BDI-II) & 22.042 & 15.298 & 7.167 & 6.657 & 4.368 & 46 & $<.001^{\mathrm{b}}$ & 1.261 \\
\hline Self-compassion (SCS) & 2.471 & .814 & 3.226 & .747 & -3.315 & 45 & .002 & -.967 \\
\hline Imagination (SUIS) & 60.750 & 14.845 & 56.667 & 9.703 & 1.128 & 46 & .265 & .326 \\
\hline Current co-morbidity [Y: N (\% yes)] & $15: 9(63 \%)$ & & - & & & & & \\
\hline
\end{tabular}

$C$ - $O C D$ washing subtype of obsessive-compulsive disorder, $H C$ healthy controls, $Y$-BOCS Yale-Brown obsessive-compulsive scale, FEE Fragebogen zur Erfassung der Ekelsensitivität (Disgust propensity), STAI-T state-trait anxiety inventory-trait version, BDI-II beck depression inventory II, SCS self-compassion scale, SUIS spontaneous use of imagery scale

${ }^{a}$ Educational level was recorded in four levels matching the German school system from 1 [highest secondary school level achieved (Abitur)] to 4 [= basic secondary school level achieved (Hauptschule)]

${ }^{\mathrm{b}}$ Levene's test is significant $(P<.05)$, suggesting a violation of the equal variance assumption

of Leipzig $(n=8)$ and through advertisements online $(n=2)$. Two participants only completed the first session, because they left their clinics afterwards. The diagnoses of OCD and potential co-morbid disorders, were assessed according to DSM-IV criteria, and based on a multimodal clinical consensus procedure including an SCID-based semi-structured clinical interview (SCID, Structured Clinical Interview for DSM-IV; German: Wittchen et al., 1997), questionnaires and behavioral observation by trained experts from the Schoen-Klinik hospital in Bad Bramstedt. The C-OCD group comprised 20 females (83\%) and 4 males (17\%), with an average age of 33.792 years $(S D=13.114)$. Thirteen patients (43\%) reported comorbid disorders, which matched the following DSM-5 Axis I diagnoses: current major depression disorder (MDD, $n=4,13.3 \%$ ), MDD with partial remission $(n=7,23.3 \%)$ and dysthymia $(n=1)$, as well as panic disorder $(n=1)$. Ten participants were receiving outpatient treatment and 14 were receiving inpatient treatment at the time of assessment. $67 \%$ of the participants were receiving medical treatment $(n=16)$, with 14 being on SSRI medication, one being on SNRI medication and one being on antidepressant medication. 63\% participants had a comorbid disorder $(n=15)$, with 12 participants being diagnosed with a comorbid depression and three participants with a comorbid panic disorder.

\section{Healthy Controls}

The healthy control group consisted of 24 participants, who were matched to the C-OCD group by age, gender and level of school education. The participants were recruited using a University of Leipzig internal database. The absence of any Axis I psychiatric disorder was ensured by accurately screening and interviewing the participants using the Structural Clinical Interview for DSM. -IV (SCID; German: Wittchen et al., 1997). The healthy control group consisted of 20 females (83\%) and 4 males (17\%) and the average age was 33.792 years $(S D=13.403)$.

\section{Comparison of the Two Groups}

The two groups were not statistically different with respect to age, $t(45.978)=0, p=1, d=0$, highest level of school education, $t(46)=0, p=1, d=0$, days between the sessions, $t(44)=-0.203, P=-0.840, d=0.060$, or their habitual use of imagery (SUIS), $t(46)=1.128 ; p=0.265, d=0.326$. Both groups had exactly the same gender ratio [20 females:4 males (17\%)]. On the other hand, the two groups did differ in any of the other demographic or clinical data, which are presented in Table 1. 


\section{Measures}

\section{Yale-Brown Obsessive-Compulsive Scale (Y-BOCS)}

The severity of obsessive and compulsive symptoms was classified by clinician-rated assessment, using the German version (Hand \& Büttner-Westphal, 1991) of the Yale-Brown Obsessive-Compulsive Scale (Y-BOCS; Goodman et al., 1989). In it, 10 items are rated on a 5-level scale to assess the severity of OCD symptoms, resulting in a score between 0 (no symptoms), and 40 (extreme symptoms). The scale has an excellent internal consistency $(\alpha=0.91)$.

\section{Disgust Propensity (Fragebogen zur Erfassung der Ekelsensitivität, FEE)}

The level of disgust propensity was assessed by applying the 37 item, scaled Fragebogen zur Erfassung der Ekelsensitivität (FEE; German: Schienle et al., 2002; Schienle et al., 2020; English: Questionnaire for the Assessment of Disgust Propensity, Goetz et al., 2013; Olatunji et al., 2011), which ranges from 0 (not disgusting) to 5 (very disgusting). The measure was used to assess five disgust categories: Death, bodily excretion, spoilage, hygiene and oral defence. The FEE has been reported to have an excellent internal consistency (Cronbach's $\alpha>0.9$ ).

\section{Beck Depression Scale-II (BDI-II)}

The Beck Depression Scale-II (BDI-II; German: Beck et al., 1996; Hautzinger et al., 2006) was used to measure the severity of depressive symptoms. The BDI-II is a selfreport scale which uses 21 items, rated from 0 to 3 , to assess symptoms of depression. The German translation has a high internal consistency (Cronbach's $\alpha>0.84$ ).

\section{State-Trait Anxiety Inventory-Trait Version (STAI-T)}

The State-Trait Anxiety Inventory-Trait Version (STAI-T; German: Laux et al., 1981) was applied to measure the level of negative affectivity. The STAI-T is a self-report scale, which uses 20 items, rated from 0 (never) to 4 (very), to assess anxiety-related symptoms. The German translation has a high internal consistency (Cronbach's $\alpha>0.84$ ).

\section{Self-compassion Scale (SCS)}

The Self-Compassion Scale (SCS; Hupfeld \& Ruffieux, 2011) was applied to measure the habitual use of self-compassion. The answers are given on a 5-point Likert scale, ranging from 0 (occasionally) to 4 (most of the time). The SCS has been reported to have a high internal consistency (Cronbach's $\alpha>0.81$ ).
Spontaneous Use of Imagery Scale (SUIS)

The Spontaneous Use of Imagery Scale (SUIS; German: Görgen et al., 2016; Reisberg et al., 2003) was used to assess the habitual use of imagery. The answers were given using a 5-point Likert scale, ranging from 1 (always) to 5 (never). The German revision by Görgen et al. (2016), differs from the original SUIS by having additional items, results in a 17-item measurement, which has been reported to have a high internal consistency (Cronbach's $\alpha>0.85$ ). Participants scored mean values between 1.6 and 4.9 on this questionnaire. Accordingly, there was no person who never experiences imagination in everyday life."

\section{Experimental Design}

The influence of imagery rescripting and imagery selfcompassion on disgust reduction was tested in a mixed subject design. While the differences between the C-OCD sample and the matched control sample, were analyzed by a between-subject design, the actual experiment was performed using a within-subject design, whereby each participant performed each of the three experimental conditions, on both days, in a randomized order. Therefore, two data points for each experimental condition were recorded for each participant. The study was approved by the local ethics committee of the University of Leipzig (2019.03.05_eb_3) and therefore the research was conducted in accordance with the 1964 Helsinki Declaration. We have reported how we determined our sample size, all data exclusion (if any), all manipulations, and all measures in the study.

\section{Stimuli and Material}

Fourteen pictures were selected from the validated DisgustRelaTed-Images database (DIRTI, Haberkamp et al., 2017). ${ }^{1}$ The pictures were associated with fourteen questions about disgust-related situations, which participants answered before the actual experiment began. This was supposed to ensure that only pictures that were individually regarded as really disgusting, were presented. The questions were related to typical contamination-related disgust categories, like spoilage (e.g. "You will find mold on the chocolate pudding.") and hygiene (e.g. "A toilet is full of urine."). The complete set of images and questions are listed in Appendix 1 . There were 7 questions and pictures for each of the

\footnotetext{
1 The Disgust-RelaTed-Images database and technical manuals (Haberkamp et al., 2017) can be obtained on request from the original authors. The DIRTI numbers for the disgust pictures used in this experiment are: 1011, 1119, 1253, 1013, 1120, 1258, 1015, 1134, 1262, 1034, 1138, 1139, 1038, 1271.
} 

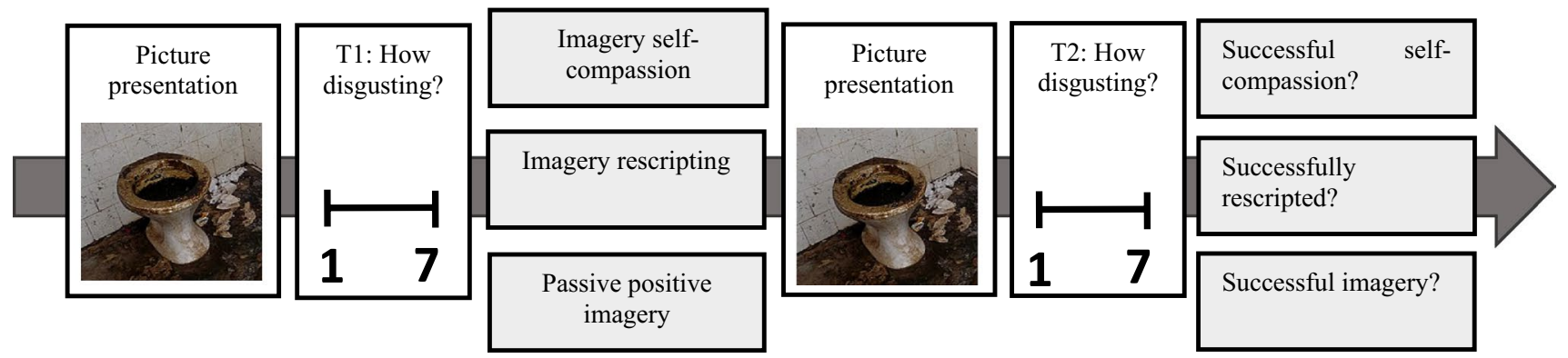

Fig. 1 Illustration of one block of the experimental procedure

two disgust categories. All the pictures were $16 \mathrm{~cm}$ wide and $12 \mathrm{~cm}$ high and were presented on a white, $30.5 \mathrm{~cm}$ wide and $13.5 \mathrm{~cm}$ high, screen. The participants were seated in front of the screen, about $50 \mathrm{~cm}$ from it, and responded by using a keyboard. The MATLAB (C) based PsychToolbox (Brainard, 1997; Kleiner et al., 2007; The MathWorks Inc., 2019) was used to run the experiment on a ThinkPad Laptop with a 14" TFT monitor.

\section{Procedure}

As in the study carried out by Fink et al. (2018), the experiment started with 14 written questions, which were used to select the six pictures to be presented in the experiment (see Section "Procedure"). On the first day, the participants were first informed of the details of the study and the test subjects' written consent to participation was obtained (informed consent was given). The participants then had to fill out the questionnaires listed above. So that the disgusting images caused an aversive experience for the test person, they were individually selected by means of an a priori survey of different disgust categories (see Section "Stimuli and Material"). Thereafter, the participants were instructed to look at the screen, on which the individually selected disgusting picture was presented for $10 \mathrm{~s}$. The participants were then asked to indicate how much the picture disgusted them on a 7-point Likert scale $(0=$ not at all, $6=$ very disgusted $)$. One of the three experimental conditions was then performed (imagery self-compassion, imagery rescripting, passive positive imagery condition, see section "Experimental Condition: Imagery Rescripting", "Experimental Condition: Imagery Self-Compassion", "Experimental Condition: Passive Positive Imagery Condition"), followed, on both days, by the two other intervention conditions, for which audible instructions were given over headphones, in a randomized order. The target picture was shown again for $10 \mathrm{~s}$ after each experimental condition, and the participants were asked to indicate, again on a 7-point Likert scale, how disgusted by the picture they now were. Finally, all the participants were asked to write down what they had actually done during the intervention on a white sheet of paper (e.g. I thought of something else), to determine whether the change in their disgust experience was due to the intended manipulation or another internal process. A new disgust picture was selected and shown for each session. Each participant performed all the three experimental conditions two times, over 2 days. The experimental conditions were performed in a randomized order, and none were repeated on the same day. The same picture was presented before ( $\mathrm{t} 1)$ and after $(\mathrm{t} 2)$ the experimental condition in each experimental block. Therefore, each participant saw a total of six pictures. The two-session design was used to control for reliability and sequence effects through withinperson repetition. The period of at least 1 week between sessions was chosen to reduce memory effects of the interventions. The number of days roughly aligns with the study by Fink et al. (2018). The course of the experiment is shown as an example in Fig. 1.

\section{Experimental Condition: Imagery Rescripting}

In the imagery rescripting (ImR) condition, the subjects were instructed to transform an aversive inner image (e.g. a disgusting image) into a neutral or positive inner image (Schmucker \& Köster, 2015). The same intervention had already been used in the studies by Fink et al. (2018) and Fink and Exner (2019). In these earlier studies, it was shown that imagery rescripting was superior to a distracting task for reducing the experience of disgust. The duration of the procedure was 6:30 min in total. A transcript of the instructions is attached in Appendix 2.

\section{Experimental Condition: Imagery Self-Compassion}

In the imagery self-compassion condition, the subjects were instructed in acting techniques from compassion focused therapy (Gilbert, 2013). Here, the subject had to imagine acting as a compassionate version of themselves, as if they were portraying a distinct theatrical role. This compassionate person was characterized by wisdom, sensitivity, tolerance, warmth, kindness and helpfulness. At the end, the 
subject was re-introduced to this "compassionate self" and linked this inner self to the feeling of inner peace. The duration of the procedure was 6:49 min in total. A transcript of the instructions is attached in Appendix 3.

\section{Experimental Condition: Passive Positive Imagery Condition}

A passive positive imagery condition was performed in the present study, in which the subjects were guided to imagine their favorite hobby. The duration of the procedure was 6:26 min in total. A transcript of the instructions is attached in Appendix 4.

\section{Statistical Analysis}

\section{Quantitative Analysis}

The software R (R Core Team, 2021), was used for the statistical analysis. Several t-tests were conducted to test for group differences. The statistical investigations were tested at the $\alpha=0.05$ (two-tailed) level of significance. We calculated a necessary sample size of 44 , using gxpower (V. 3.1; Faul et al., 2007), and assuming the medium effect size from Fink et al. (2018) of cohen's $f=0.2$ for the main effect strategy, with two groups and six measurements (strategies and time), a power of 0.95 , and an $\alpha$ of 0.05 . All data is published under https://osf.io/qvm83.

An ANOVA with the factors group, time and imagery strategy were calculated for the main results and for the dependent variable disgust experience. One ANOVAs with the factors day and block was calculated for the dependent variables, disgust experience. For hypothesis 3 and 4 linear models and further ANOVAs were calculated to the dependent variable difference in disgust experience between $t 1$ and $t 2$. The effect sizes were calculated using the R package "rstatix" (Version 0.4.0; Kassambara, 2019). Whereby, the generalized eta-squares $\left(\eta^{2}\right)$ are reported. A Shapiro Wilk Test for Normality was conducted, and the normality assumption was violated for both dependent variables. However, due to sample size and the multiple measures for each participant, it is possible to assume an approximate asymptotic normal distribution for each of these variables (Field, 2013). A Levene's test for homogeneity of variance was conducted for the dependent variables across the imagery strategies. The R package "car" (Version 3.0-3; Fox \& Weisberg, 2019) was used for the Levene test. This test was not significant $(P>0.05)$, so homogeneity of the residual variances for the two groups is assumed.

\section{Qualitative Analysis}

The written description and the actual use and success of the instructed emotion-regulation strategies were analyzed using a qualitative content analysis. For coding, iteratively and theoretical based qualitative categories for both the ImR condition and the imagery CFT, were created by using an empirically and theoretically guided category formation (Appendix 5, Mayring, 2010). The passive positive imagery condition was not included in the content analysis because the research question was focused on the possible therapeutic approaches. Two raters, who were instructed and trained in rating the written descriptions according to the protocol, marked the category column which best represented the participant' description of their experience during the task. It was possible to rate two or more categories per comment, since in some cases, different qualities were described. An almost excellent agreement between the two raters was calculated by using the two-way random effect model and "single rater" unit $(\kappa=0.9, P<0.001)$.

\section{Results}

\section{Testing for Baseline Effects}

To test for baseline effects, a $3 \times 2$ ANOVA with the dependent variable initial disgust experience (t1) revealed no baseline differences for imagery strategy, but a significant baseline difference for group, $F(1,126)=21.831, P<0.001$, $\eta^{2}=0.15$. A further investigation on the initial disgust experience ( $\mathrm{t} 1)$, revealed that being in the healthy control group was associated with a smaller disgust experience at $\mathrm{t} 1, M=4.319, S D=0.81$, compared to being in the clinical group, $M=5.219, S D=0.611, t(42.77)=-4.344, P<0.001$, $d=1.254$. These results show that individuals did not rate images differently at baseline between the experimental conditions (within-person), though there were between-subject differences between the two groups for the initial disgust experience.

\section{Hypothesis 1 and 2: The Impact of Emotion Regulation on Disgust Reduction Across Groups and Imagery Strategies}

For disgust experience, which was operationalized with the subjectively reported disgust experience on the 7-point Likert-scale, a $3 \times 2 \times 2$ ANOVA with the within-subject factors time ( $\mathrm{t} 1, \mathrm{t} 2)$, and imagery strategy (imagery rescripting, imagery compassion, passive positive imagery) and the between-subject factor group (healthy controls, clinical group), revealed that there were significant main effects for time, $F(1,46)=34.702$., $P<0.001, \eta^{2}=0.09$, and for group, 


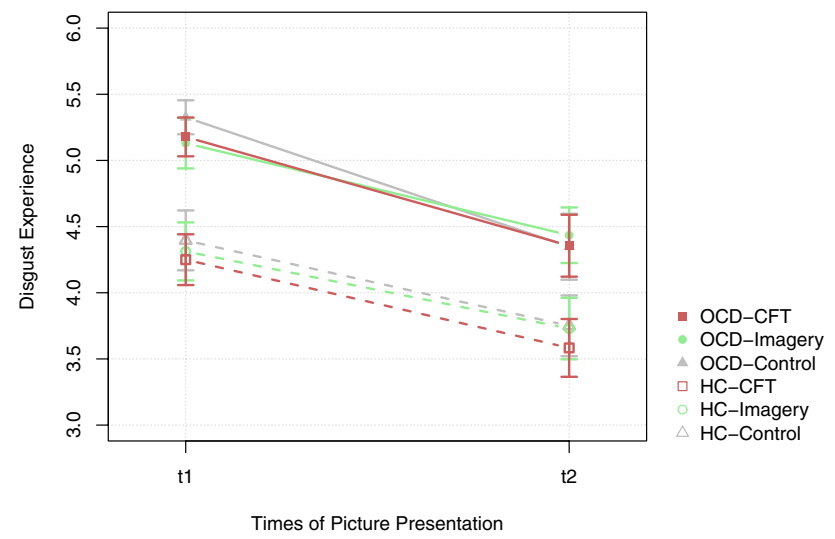

Fig. 2 Means and standard deviations of the disgust experience between $\mathrm{t} 1$ and $\mathrm{t} 2$ across the three experimental conditions for the two groups (COCD contamination-based obsessive-compulsive disorder). Disgust ratings were given on a scale between 0 and 6

$F(1,46)=12.243 ., P=0.001, \eta^{2}=0.12$, but not for imagery strategy and no interaction became significant (Fig. 2). Further investigation into the main effect of time on disgust experience, revealed that disgust experience on $t 1$, $M=4.771, S D=1.061$, was significant higher compared to $t 2, M=4.056, S D=1.349, t(47)=5.94, P<0.001, d=0.694$. More specifically, all three imagery strategies reduced disgust in a medium effect size range: imagery rescripting $(d=0.528)$, imagery self-compassion (CFT, $d=0.561)$, and the passive positive imagery condition $(d=0.6)$. Further investigation into the effect of group on disgust experience using planned contrasts, revealed that being in the healthy control group was associated with a significant smaller overall disgust experience, $M=4.003, S D=0.846$, than being in the clinical group, $M=4.818, S D=0.772, t(54.62)=3.489$, $P=0.001, d=1.007$. The main effects on time and group stayed significant when controlling for individual traits in ANCOVAs. However, these results are not reported in more detail due to the insufficient power and would need to be examined in more detail in subsequent studies.

An additional $2 \times 3$ ANOVA with the within-subject variables day ( 1 or 2 ) and block ( 1 or 2 or 3 ), had revealed a significant main effect of $d a y, F(1,43)=23.459$., $P<0.001$, $\eta^{2}=0.06$, and block, $F(2,86)=8.929 ., P<0.001, \eta^{2}=0.04$, on the subjectively reported disgust experience, but the interaction became not significant. Further investigation into the main effect of day on disgust experience, revealed that disgust experience on day $1, M=4.733, S D=0.095$, was higher compared to day 2, $M=4.04, S D=1.08$. Further investigation into the main effect of block on disgust experience, revealed that disgust experience during block $1, M=4.01$, $S D=1.15$, was smaller compared to block $2, M=4.568$, $S D=1.035$, and block 3, $M=4.667, S D=1.066$.

\section{Hypothesis 3: Regression Effects of Individual Trials on Disgust Reduction and First Disgust Experience}

The habitual use of imagery $(b=-0.018, P=0.004)$ and disgust propensity ( $b=0.008, P=0.01$ ) were significant predictors of the difference in disgust experience between $t 1$ and $t 2$ in a linear regression model. A higher habitual use of imagery trait was associated with more disgust reduction between $\mathrm{t} 1$ and $\mathrm{t} 2$, and also that higher disgust propensity was associated with less disgust reduction between $\mathrm{t} 1$ and $\mathrm{t} 2$. All other traits were not significant predictors. The overall model fit was $\mathrm{R}^{2}=0.087$.

When initial disgust experience $(\mathrm{t} 1)$ was predicted in a linear regression model, disgust propensity $(b=0.015$, $P<0.001)$ and negative affectivity $(b=0.037, P=0.028)$ were significant predictors. Therefore, higher disgust propensity, as well as higher negative affectivity, were associated with a stronger initial disgust experience (t1). All other traits were not significant predictors. The overall model fit was $\mathrm{R}^{2}=0.108$.

\section{Hypothesis 4: Qualitative Results}

In order to present the results referring to the dichotomous variable (e.g. in the CFT condition, "Were you able to build up a compassionate self?" yes/no), qualitative response, group and imagery strategy were tested in the context of a $3 \times 2 \times 2$ ANOVA with mixed measures on the dependent variable disgust reduction between $t 1$ and $t 2$. Here, a significant main effect was found for qualitative response with respect to disgust reduction between $t 1$ and $t 2, F(1$, $275)=6.759, P=0.009, \eta^{2}=0.04$. According to this, the participants who themselves stated that they had successfully completed the task, $M=-0.834, S D=1.186$, reduced their disgust experience between $\mathrm{t} 1$ and $\mathrm{t} 2$ more strongly across all conditions and groups, than those who stated that they had not successfully completed the task, $M=-0.375, S D=0.787$. However, when considering the frequencies with which the subjects rated the interventions as successful or unsuccessful, a $3 \times 2$ ANOVA with mixed measures shows a significant main effect for imagery strategy, $F(2,92)=3.014, P=0.009$, with more successful ratings in the passive positive imagery condition $(n=78)$ and the ImR condition $(n=76)$, than in the CFT condition $(n=63)$. In addition there is a significant main effect for group, $F(1,56)=5.593, P=0.022$, as there were more successful responses in the healthy group $(n=122)$ compared to the clinical group $(n=95)$. Overall, an average of 42.5 statements about helpful aspects of the CFT strategy and 38.5 statements about difficulties with the same strategy, were encoded. For ImR, it was possible to encode an overall average of 62.5 statements on helpful aspects and 14.5 statements on those that caused difficulties. Participants did 
Table 2 Results of the qualitative content analysis

\begin{tabular}{|c|c|c|}
\hline Strategy & Category (definition) & Mentioned \\
\hline \multicolumn{3}{|c|}{ Compassion-self (CFT) } \\
\hline \multirow[t]{3}{*}{ Helpful } & Self-kindness (understanding, warmth, kindness, friendliness, inner strength and appreciation) & $62.4 \%(\mathrm{n}=26.5)$ \\
\hline & $\begin{array}{l}\text { Mindfulness (acceptance, mindfulness and non-judgmental observation, calmness and taking } \\
\text { perspective) }\end{array}$ & $27.1 \%(\mathrm{n}=11.5)$ \\
\hline & $\begin{array}{l}\text { Common Humanity (empathy, compassion (for others), the feeling of connectedness and com- } \\
\text { munity) }\end{array}$ & $10.95 \%(n=4.5)$ \\
\hline \multirow[t]{5}{*}{ Difficult } & External structure of the exercise & $24.68 \%(n=9.5)$ \\
\hline & No access to self-compassion & $22.08 \%(\mathrm{n}=8.5)$ \\
\hline & Lack of imagination & $20.78 \%(\mathrm{n}=8)$ \\
\hline & Internal resistance & $20.78 \%(n=8)$ \\
\hline & Lack of concentration & $11.96 \%(n=4.5)$ \\
\hline \multicolumn{3}{|c|}{ Imagery rescripting (ImR) } \\
\hline \multirow[t]{3}{*}{ Helpful } & $\begin{array}{l}\text { Activating the experience of a positive image (the positive re-evaluation of the image, the creat- } \\
\text { ing of a positive image, to focus on positive features or even the idea of pleasant smells) }\end{array}$ & $56.6 \%(\mathrm{n}=35.5)$ \\
\hline & $\begin{array}{l}\text { Activating the imagination and using it as a tool (possible actions that were tried out within the } \\
\text { imagination, such as dissolving the image, exchanging objects or transforming them) }\end{array}$ & $37.6 \%(\mathrm{n}=23.5)$ \\
\hline & Protective cover (aspect of security and protection against threats) & $5.6 \%(n=3.5)$ \\
\hline \multirow[t]{3}{*}{ Difficult } & External structure of the exercise & $44.44 \%(n=8)$ \\
\hline & Difficulties in disengaging from the disgusting stimulus & $44.44 \%(n=8)$ \\
\hline & Lack of imagination & $11.11 \%(\mathrm{n}=2)$ \\
\hline
\end{tabular}

not give enough information about why the passive positive imagery condition was helpful or difficult to implement and these where therefore not analyzed. Participants reported aspects in all of our a priori theoretically derived categories, albeit with varying frequency. How often each category was mentioned is shown in Table 2.

\section{Discussion}

The aim of the present study was to investigate whether there are differences in the mechanisms and effectiveness of different imagery strategies (imagery rescripting, imagery self-compassion, passive positive imagery condition) for reducing disgust in the context of contamination-related obsessive-compulsive disorder (C-OCD). With regard to the lack of disgust reduction in the "Fish counting"-control condition of Fink et al. (2018), who used the same experimental design, the results show that all three interventions were equally helpful for reducing strong feelings of disgust, which means we have to reject our hypothesis 1 . Further, the results show that people with $\mathrm{C}-\mathrm{OCD}$ have a stronger initial disgust experience and that they can also reduce the disgusting experience to the same extent than the healthy control sample, which is contrary to our hypothesis 2 . In line with hypothesis 3 , higher habitual use of imagery is a positive predictor of greater disgust reduction, while stronger trait disgust propensity tends to make disgust reduction more difficult. People who tend to have a stronger anxiety or disgust propensity trait also experience more initial disgust. Also, in line with hypothesis 4 , the results of the elaborate content analysis show that the theoretically derived mechanisms were reported by the subjects and had an impact on the success or failure of the strategies.

First, the results show that all three imagery strategies are equally effective for reducing disgust. This is contrary to our expectation, that the disgusting image would be changed most directly in the ImR condition and therefore, that this strategy would have the greatest effect, while the passive positive imagery condition was expected to have the most indirect and therefore weakest, effect. Still, the overall disgust reduction is similar to, or more pronounced than, the effect of imagery rescripting ( $\operatorname{ImR})$ in previous studies. In the study by Fink et al. (2018), it was shown that cognitive appraisal $(d=0.255)$ and $\operatorname{ImR}(d=0.202)$ reduced disgust with small effects, which were stronger than the effect size for a control condition in which the subjects were instructed to count fish in a video aquarium $(d=0.096)$. In the study by Fink and Exner (2019), which only had a healthy sample, there was a small effect for the disgust reduction in the same control condition $(d=0.163)$, but a medium effect for the ImR condition $(d=0.415)$. In the present study, all three imagery strategies reduced disgust in a medium effect size range: $\operatorname{ImR}(d=0.528)$, imagery self-compassion (CFT, $d=0.561$ ), and the passive positive imagery condition $(d=0.6)$. In the context of the short intervention, these are first indications that general imagery processing is a basic factor that can help change disgust experience. 
The results of the content analysis are in accordance with our predictions and show that participants reported the assumed mechanisms in the CFT condition (a positive self-image when activating self-kindness and mindfulness) and in the ImR condition (self-efficacy and self-control in experiencing the rescripted positive image and imagination as a "tool"). The finding that subjects found the very core of underlying theories of the two strategies helpful, supports (a) the theory that self-compassion can be understood as a strategy for preventing the individual from identifying excessively with thoughts and feelings and thus becoming trapped and carried away by negative reactions and (b) that ImR can cause a change in the image's meaning, which in turn changes the associated emotions. However, we were surprised by the equally effective passive positive imagery condition. Here there is evidence from the findings that this condition was even more often self-assessed as being a successful strategy. It can be assumed that this is a non-specific distraction effect, which has a powerful, short-term effect in handling aversive emotions (Salkovskis, 1999). On the other hand, it is a further proof that activating mental images is an adequate emotion regulation strategy.

We had expected that how well the strategies fit would depend on the different traits' characteristics but the results do not show this. However, different traits did have strategyunspecific effects: Higher levels of trait disgust propensity and negative affectivity, led to a higher initial disgust experience at $\mathrm{t} 1$. This is understandable in view of the many findings on the high correlation between disgust and fear in maintaining C-OCD (Cisler et al., 2009). In general, the results show that a higher tendency to habitually use imagery is helpful in the application of imagery strategies to reduce disgust. In the study by Fink et al. (2018), the opposite effect was found, but since the effect is strategy-unspecific in the present study, this may still be the case. The higher habitual use of imagery might have been particularly helpful for the passive positive imagery condition and the CFT condition, because the mental image did not have to be actively changed in these conditions (Holmes et al., 2007). A higher disgust propensity trait, on the other hand, actually hinders changing disgust with imagery strategies, which is in accordance with the former assumptions. Although there are no effects concerning specific strategies, the results show that the ability to imagine is an important indicator for the successful use of imagery. This should be given special attention when implementing imagery strategies in therapeutic practice and, preliminary exercises should be conducted where there is doubt. Other variables that could be considered predictors of imagery success were elaborated by Kunze et al. (2019). In particular, mastery (or self-efficacy) seems to be a vestigial predictor that should also be considered more closely in future studies in the context of disgust.
There is a significant group difference in the present study: Patients with C-OCD experienced more initial and general disgust experience, but did benefit in the same way from imagery strategies than the matched, healthy controls. This is contrary to the findings of Fink et al. (2018) and could be interpreted in a way, that imagery generally reduces all levels of disgust. This is particularly interesting, because the qualitative findings show that more healthy subjects rated their implementation of the interventions as successful, than those with C-OCD. Further, the results also show that those who assessed the implementation as successful, benefited more from the interventions than those who assessed them as unsuccessful. Thus, it could also be that those patients whose self-perception is that they have benefited from the strategy, can reduce disgust much strongly and in a more enduring way, than their healthy counterparts. This would need to be investigated in future studies.

\section{Methodological Considerations and Limitations of the Experiment}

We are aware of some limitations to our study. The first limitation is the gender ratio of $83 \%$ women. A more equal gender ratio might control for disgust-specific gender effects, taking into account the idea that women tend to be more sensitive to disgust (Schienle et al., 2005). Nonetheless, exactly the same results were found by recalculating all the results and excluding the four male subjects in each group; therefore, our results have to be seen as applying primarily to women. A second limitation is that the content analysis on subjectively perceived strategies could not be applied to the passive positive imagery condition. This was because the participants did not give enough information about why the strategy was helpful or difficult to implement. In a future study, the questions should be asked in such a way that participants are more motivated to answer these questions. Third, a fundamental problem is that the 7-min interventions and 10-s picture presentations reduced the ecological validity and promoted distraction effects. In the long run, it will be important to perform longer, and more elaborate, interventions regarding idiosyncratic disgust, preferably in a face-to-face setting. Due to the current study design enduring effects of imagery could not be investigated. To test this in future studies, short interventions would have to be presented more frequently or the effect would have to be recorded in the short term (e.g., on the next day) (see the studies on imagery rescripting by Kunze et al., 2017; Siegesleitner et al., 2019). A fourth limitation could be that habituation effects could not be tested directly, because a non-imagery condition was not included. However, previous studies (Fink \& Exner, 2019; Fink et al., 2018) have shown the effectiveness of imagery rescripting compared to a habituation control condition. A methodological consideration is 
that by stringing the three blocks together, the experience of disgust was magnified, which is evident in the main effect block. Emotional sensitization by repetition of disgust experience in well known in other studies (Fink-Lamotte et al., 2020). While these processes should not have influenced the main hypotheses here due to randomization and the focus on within-block change, it is nonetheless important to keep a closer eye on this in future studies.

\section{Conclusion and Implication for Future Research}

The aim of this study was to investigate how effectively and by what mechanisms, three different imagery strategies reduced disgust in the context of C-OCD. Particularly in comparison with the results of Fink et al. (2018)—including a habituation control condition and an imagery rescripting condition-the results show that all three strategies were equally capable of reducing disgust on all levels of disgust experiencing. This provides further evidence of the benefits of imagery strategies in altering pathological disgust. The results also show that the success of imagery strategies is related to the subject's ability to use imagination. Special attention should be paid to this when implementing imagery strategies in a therapeutic setting and, in case of doubt, preliminary exercises should be performed (also in future studies). In the elaborate content analysis it was shown, that participants who reported the theoretically assumed mechanisms of the strategies and considered the intervention itself to have been a success, were better at reducing disgust. Even though it seems that "many roads lead to Rome" in the context of changing disgust through imagery, the difference between more active and more passive imagery strategies should be further investigated in future studies.

\section{Appendix 1: Picture selection questionnaire and picture numbers}

The following table refers by using examples, to two dimensions of the disgust-evoking stimuli that were used in the study. Subjects were first presented with the questionnaire items in the third column. The disgust-related pictures were selected on the basis of these results.

\begin{tabular}{|c|c|c|c|c|c|}
\hline scale & \# & $\begin{array}{l}\text { Questionnaire } \\
\text { item for preselec- } \\
\text { tion }\end{array}$ & Picture & $\begin{array}{l}\text { Valence } \\
M(S D)\end{array}$ & $\begin{array}{l}\text { Arousal } M \\
(S D)\end{array}$ \\
\hline \multirow[t]{7}{*}{ Spoilage } & 1 & $\begin{array}{l}\text { There is mouldy } \\
\text { food in front of } \\
\text { you (Vor Ihnen } \\
\text { liegt verschim- } \\
\text { meltes Essen) }\end{array}$ & 1011 & $\begin{array}{c}2.78 \\
(1.32)\end{array}$ & $3.47(2.66)$ \\
\hline & 2 & $\begin{array}{l}\text { The trash can is } \\
\text { full of urine } \\
\text { and tissues } \\
\text { (Der Mül- } \\
\text { leimer ist } \\
\text { voller Urin und } \\
\text { Taschentücher) }\end{array}$ & 1119 & $\begin{array}{c}2.57 \\
(1.32)\end{array}$ & $3.58(2.59)$ \\
\hline & 3 & $\begin{array}{l}\text { A preserving jar } \\
\text { is full of mould } \\
\text { after being } \\
\text { opened. (Ein } \\
\text { Einmachglas } \\
\text { ist nach dem } \\
\text { Öffnen voller } \\
\text { Schimmel.) }\end{array}$ & 1013 & $\begin{array}{c}2.69 \\
(1.22)\end{array}$ & $3.28(2.46)$ \\
\hline & 4 & $\begin{array}{l}\text { A friend's } \\
\text { apartment is } \\
\text { cluttered. (Die } \\
\text { Wohnung eines } \\
\text { Bekannten ist } \\
\text { zugemüllt) }\end{array}$ & 1258 & $\begin{array}{c}2.58 \\
(1.32)\end{array}$ & $3.56(2.66)$ \\
\hline & 5 & $\begin{array}{l}\text { You find mould } \\
\text { on the choco- } \\
\text { late pudding } \\
\text { (Auf dem } \\
\text { Schokoladen- } \\
\text { pudding finden } \\
\text { Sie Schimmel) }\end{array}$ & 1015 & $\begin{array}{c}2.84 \\
(1.18)\end{array}$ & $3.22(2.53)$ \\
\hline & 6 & $\begin{array}{l}\text { The food in a } \\
\text { fast food box } \\
\text { is mouldy } \\
\text { (In einer } \\
\text { Fastfoodbox } \\
\text { ist das Essen } \\
\text { verschimmelt) }\end{array}$ & 1034 & $\begin{array}{c}2.91 \\
(1.26)\end{array}$ & $3.21(2.42)$ \\
\hline & 7 & $\begin{array}{l}\text { Spoiled food is } \\
\text { covered with a } \\
\text { layer of mould. } \\
\text { (Verdorbene } \\
\text { Essen ist von } \\
\text { einer Schicht } \\
\text { Schimmel } \\
\text { belegt.) }\end{array}$ & 1038 & $\begin{array}{c}2.85 \\
(1.27)\end{array}$ & $3.14(2.48)$ \\
\hline
\end{tabular}




\begin{tabular}{|c|c|c|c|c|c|}
\hline scale & \# & $\begin{array}{l}\text { Questionnaire } \\
\text { item for preselec- } \\
\text { tion }\end{array}$ & Picture & $\begin{array}{l}\text { Valence } \\
M(S D)\end{array}$ & $\begin{array}{l}\text { Arousal } M \\
(S D)\end{array}$ \\
\hline \multirow[t]{7}{*}{ Hygiene } & 8 & $\begin{array}{l}\text { Strangers' finger- } \\
\text { nails are full } \\
\text { of dirt. (Die } \\
\text { Fingernagel } \\
\text { einer fremden } \\
\text { Person sind } \\
\text { voller Dreck.) }\end{array}$ & 1253 & $\begin{array}{c}3.23 \\
(1.32)\end{array}$ & $3.10(2.39)$ \\
\hline & 9 & $\begin{array}{l}\text { Right in front of } \\
\text { you, someone } \\
\text { has thrown up } \\
\text { on the pave- } \\
\text { ment. (Direkt } \\
\text { vor Ihnen hat } \\
\text { sich jemand } \\
\text { auf der Straße } \\
\text { erbrochen.) }\end{array}$ & 1120 & $\begin{array}{c}2.72 \\
(1.40)\end{array}$ & $3.62(2.66)$ \\
\hline & 10 & $\begin{array}{l}\text { You must use a } \\
\text { port-a-potty, } \\
\text { which is full } \\
\text { of urine. (Sie } \\
\text { müssen auf ein } \\
\text { Dixieklo, das } \\
\text { voll mit Urin } \\
\text { ist.) }\end{array}$ & 1134 & $\begin{array}{c}2.21 \\
(1.31)\end{array}$ & $4.05(2.80)$ \\
\hline & 11 & $\begin{array}{l}\text { There's a lot } \\
\text { of hair in the } \\
\text { shower strainer. } \\
\text { (Im Duschsieb } \\
\text { befinden sich } \\
\text { viele Haare.) }\end{array}$ & 1262 & $\begin{array}{c}3.36 \\
(1.28)\end{array}$ & $2.81(2.23)$ \\
\hline & 12 & $\begin{array}{l}\text { A public toilet } \\
\text { that you visit } \\
\text { is full of excre- } \\
\text { ment and toilet } \\
\text { paper. (Eine } \\
\text { öffentliche } \\
\text { Toilette, die } \\
\text { Sie besuchen, } \\
\text { ist voll mit Kot } \\
\text { und Klopapier.) }\end{array}$ & 1138 & $\begin{array}{c}2.07 \\
(1.24)\end{array}$ & $4.30(2.83)$ \\
\hline & 13 & $\begin{array}{l}\text { A toilet is full } \\
\text { of urine. (Eine } \\
\text { Toilette ist voll } \\
\text { Urin.) }\end{array}$ & 1139 & $\begin{array}{c}2.71 \\
(1.30)\end{array}$ & $3.46(2.65)$ \\
\hline & 14 & $\begin{array}{l}\text { A toilet is full } \\
\text { of toilet paper, } \\
\text { excrement, and } \\
\text { urine. (Eine } \\
\text { Toilette ist vol- } \\
\text { ler Toilettenpa- } \\
\text { pier, Kot und } \\
\text { Urin.) }\end{array}$ & 1271 & $\begin{array}{c}2.20 \\
(1.30)\end{array}$ & 4.09 (2.79) \\
\hline
\end{tabular}

Appendix 2: Imagery rescripting procedure

\begin{tabular}{|c|c|c|}
\hline Instructions & Function & Time \\
\hline $\begin{array}{l}\text { Envision the picture before } \\
\text { your inner eye } \\
\text { To do so, you can either } \\
\text { close your eyes or look at } \\
\text { the screen } \\
\text { Imagine in as much detail } \\
\text { as possible, what you can } \\
\text { see, hear, feel and smell }\end{array}$ & $\begin{array}{l}\text { Introduction, activation of } \\
\text { experiencing }\end{array}$ & $0: 00-0: 31$ \\
\hline $\begin{array}{l}\text { Imagine how you enter } \\
\text { the picture and how the } \\
\text { object presented becomes } \\
\text { real } \\
\text { Your body is surrounded } \\
\text { by a protective cover. } \\
\text { Nothing can penetrate the } \\
\text { cover to threaten you } \\
\text { Imagine your protective } \\
\text { cover in as much detail } \\
\text { as possible. What color is } \\
\text { it? How big is it? }\end{array}$ & $\begin{array}{l}\text { Activation of imagery } \\
\text { and trial of imagery as a } \\
\text { tool. Protective cover as } \\
\text { protection against threat; } \\
\text { increases feelings of } \\
\text { control }\end{array}$ & $0: 31-1: 25$ \\
\hline $\begin{array}{l}\text { Please move yourself, } \\
\text { inside the picture, } \\
\text { towards the object } \\
\text { presented }\end{array}$ & \multirow[t]{4}{*}{$\begin{array}{l}\text { Activation of imagery and } \\
\text { working with imagery } \\
\text { as a tool }\end{array}$} & \multirow[t]{4}{*}{$1: 25-2: 03$} \\
\hline $\begin{array}{l}\text { Use your imagination to } \\
\text { change the size of the } \\
\text { presented object }\end{array}$ & & \\
\hline $\begin{array}{l}\text { First, make the object very } \\
\text { tiny }\end{array}$ & & \\
\hline $\begin{array}{l}\text { Then make it huge } \\
\text { Return it to its normal size }\end{array}$ & & \\
\hline
\end{tabular}

Please notice exactly what the object looks like, how it sounds and how it smells

If you are disgusted, try to tolerate this feeling

Please try to change the object so that it is no longer disgusting

In your imagination, you can be a wizard. You can change everything! You decide, what happens in your imagination

You can include new elements and you can erase elements in your imagination

You can change the environment, or you can change the object into something completely different

There are no limits. Let your imagination go wild!

Activation of experiencing

2:03-2:28 and feeling of disgust

Activation of experiencing and feeling of disgust

Imagery Rescripting; 2:40-4:09 testing different options in handling imagery rescripting; increase feelings of control concerning mental experiences

- 


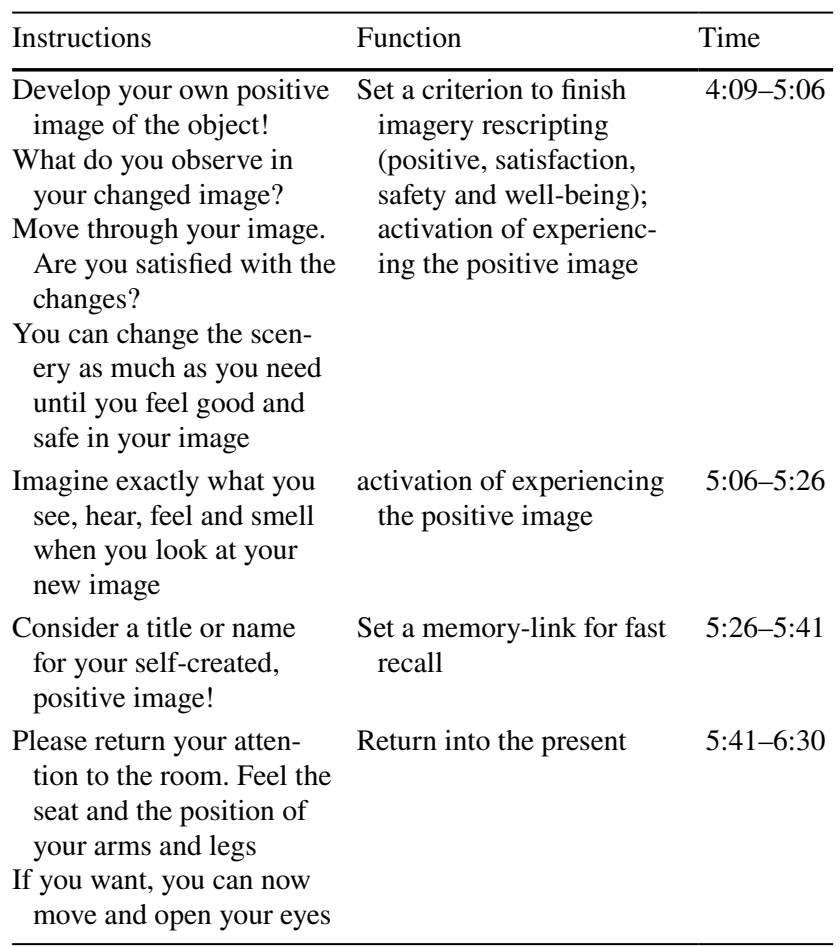

\section{Appendix 3: Imagery self-Compassion procedure}

\begin{tabular}{lll}
\hline Instructions & Function & Time \\
\hline $\begin{array}{l}\text { Picture the image in your } \\
\text { mind }\end{array}$ & $\begin{array}{c}\text { Introduction, Activate } \\
\text { experience }\end{array}$ & $0: 00-0: 24$ \\
$\begin{array}{l}\text { You can either close your } \\
\text { eyes or look at the screen }\end{array}$ & \\
Paint yourself as exactly as & & \\
possible, from what they & \\
see, hear, feel and smell & \\
Now imagine yourself & Activate imagination and & $0: 25-1: 15$ \\
entering this picture and & try it out as a "tool"; & \\
what is depicted becomes & protective cover against & \\
real & possible threat; stronger & \\
Your body is surrounded & sense of control & \\
by a protective cover & \\
Imagine that nothing can & \\
penetrate this protective & \\
cover and threaten you & \\
Take a good look at your & \\
protective cover & \\
What is it made of; what & \\
colour is it; how big is & \\
this cover? &
\end{tabular}

\begin{tabular}{lll}
\hline Instructions & Function & Time \\
\hline $\begin{array}{l}\text { Now imagine you are an } \\
\text { actor in training }\end{array}$ & $\begin{array}{l}\text { Activate imagination } \\
\text { and try it out as a "tool" }\end{array}$ & \\
As an actor, you have been & & \\
able to evoke certain pos- & \\
itive feelings, thoughts & \\
and motives in your- & \\
self-in order to achieve & \\
exactly these characters & \\
from the inside out & \\
Focus on how the character & \\
thinks and looks at the \\
world \\
The character we are now \\
developing is a compas- \\
sionate person who is \\
especially characterized \\
by compassion for him- \\
self and for other people
\end{tabular}

Concentrate on your task as an actor, to portray a "compassionate person" Imagine how they are calm and talk about wisdom and grounding serenity

How you sense and have the ability to tolerate difficulties and face challenges. Feel the warmth and goodness and the understanding that you bring to yourself

Take an unprejudiced attitude towards yourself and the things around you

Feel the deep desire to relieve suffering, to make changes and to help others and to support themselves and other people in growing and living

Try to put a compassionate expression on your face, such as a light smile, or any other expression that suits you

Imagine how you expand as you become more powerful, mature, wise, and have more confident authority

Feel the warmth in your body and linger in this moment for a moment
Development and activation of a compassionate person
Activating experience for a $\quad 3: 48-4: 44$ positive self-image (positive, satisfactory, security, well-being) 


\begin{tabular}{lll}
\hline Instructions & Function & Time \\
\hline $\begin{array}{l}\text { Now go through these } \\
\text { qualities again slowly }\end{array}$ & $\begin{array}{c}\text { Intensify experience for a } \\
\text { positive self-image }\end{array}$ & $4: 45-5: 41$ \\
and imagine that they & & \\
had grown in you a little & & \\
bit, as if you could really & & \\
feel them: & & \\
Wisdom, sensitivity, seren- & & \\
ity, tolerance, warmth, & \\
kindness, helping & \\
You can imagine your & \\
"compassionate self" & \\
again and think of a feel- & \\
ing of inner peace and a & \\
supporting voice & \\
Now give your self- & Set memory anchor for & \\
created, positive figure & quick recall & \\
a name. You can now & \\
recall the imagined & \\
person again and again to & \\
support you in your fears & \\
and resistance & \\
Now slowly return your & return to the present \\
attention to the room. & \\
Feel the seat and the \\
position of your arms \\
and legs. You can move \\
and open your eyes. \\
Keep your compassion- \\
ate character and his \\
name in mind. You can \\
slip into this role again \\
and again \\
\hline
\end{tabular}

\section{Appendix 4: Imagery control condition procedure}

\begin{tabular}{lll}
\hline Instructions & Function & Time \\
\hline $\begin{array}{l}\text { Picture the image in your } \\
\text { mind }\end{array}$ & $\begin{array}{c}\text { Introduction, Activate } \\
\text { experience }\end{array}$ & $0: 00-0: 31$ \\
You can either close your & \\
eyes or look at the screen & & \\
Paint yourself as exactly as & & \\
possible, from what they & \\
see, hear, feel and smell & \\
\hline
\end{tabular}

\begin{tabular}{lll}
\hline Instructions & Function & Time \\
\hline Now imagine yourself & Activate imagination and & $0: 32-1: 40$ \\
entering this picture and & $\begin{array}{c}\text { try it out as a "tool"; } \\
\text { what isdepicted becomes } \\
\text { protective cover against }\end{array}$ & \\
real & possible threat; stronger & \\
Your body is surrounded & sense of control &
\end{tabular}

by a protective cover

Imagine that nothing can penetrate this protective cover and threaten you

Take a good look at your protective cover

What is it made of; what colour is it; how big is this cover?

Now imagine yourself pursuing your favourite hobby. Remember, it doesn't matter what you choose. Let all positive feelings, thoughts and motives come up and concentrate on them

Now choose the hobby that is most good to you. Say in your mind what you have chosen

Now direct your full concentration to your favourite hobby. Imagine your favourite hobby exactly. What does it consist of; what activity or activities do you pursue? Imagine exactly what you see, hear, feel and smell there now

Now perceive your physical sensations

Perceive which thoughts come to you

Perceive how you feel

Stay in the moment for a moment and enjoy the pleasure and contentment that spreads within you

Now go through these properties again, slowly

Now slowly return your attention to the room. Feel the seat and the position of your arms and legs. You can move and open your eyes. Keep the positive image in mind
Activate imagination and try it out as a "tool"

Activation of your favourite hobby

Activating experience of the positive hobby

Intensify experience for a positive hobby

Set memory anchor for quick recall

return to the present 


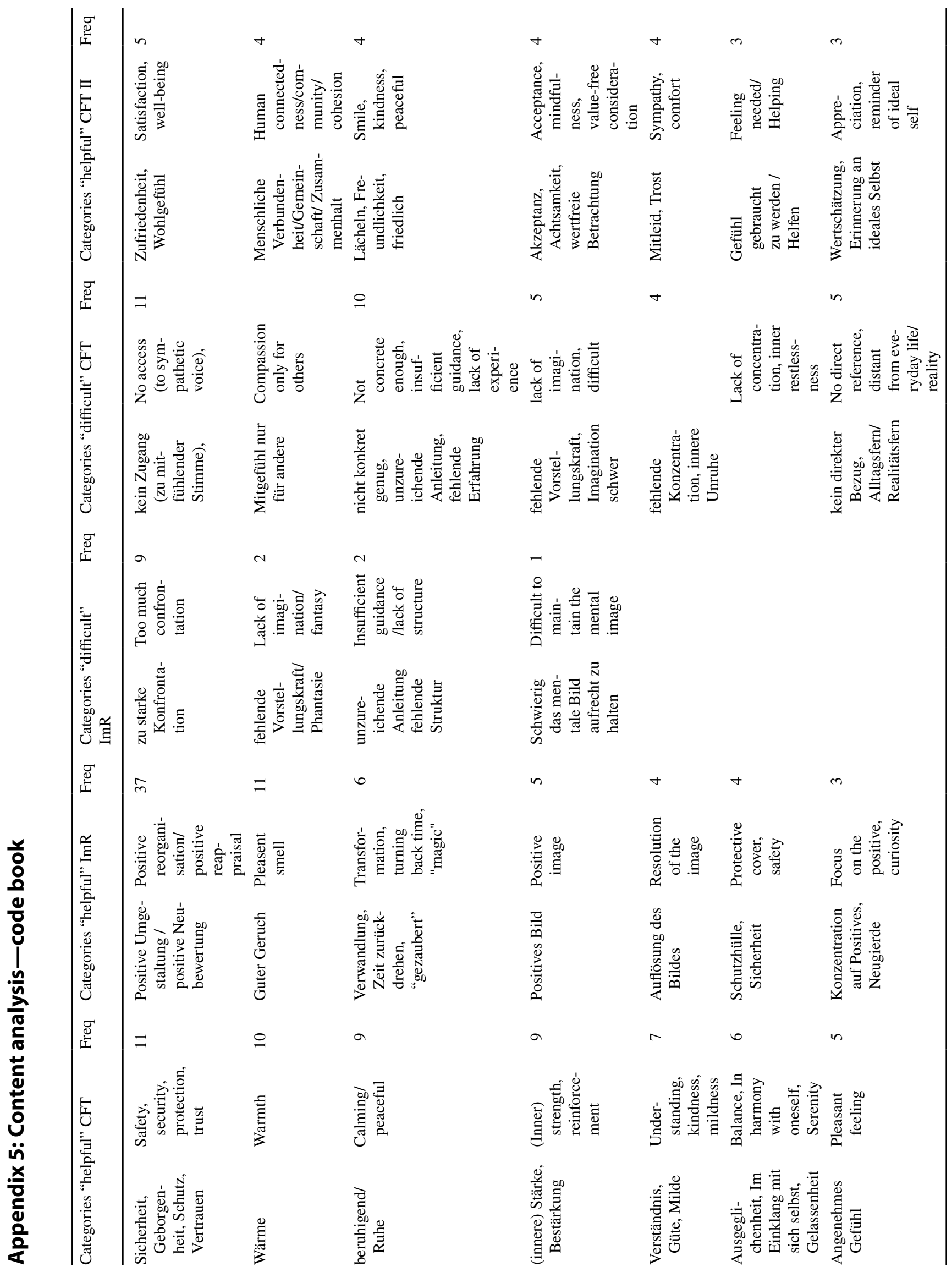




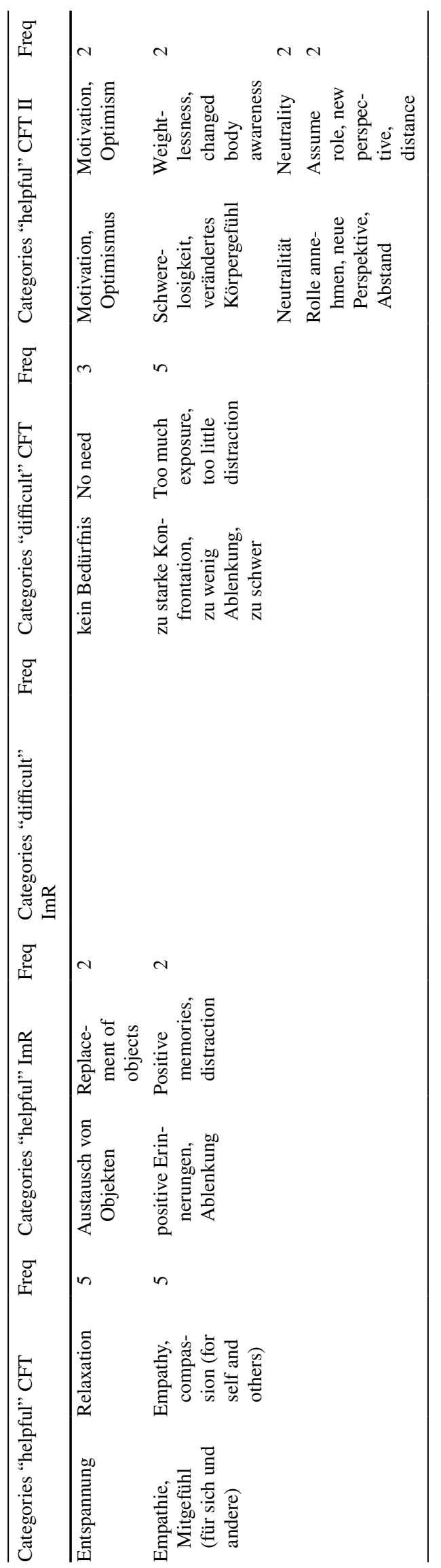

Acknowledgements First, we would like to thank the individuals who participated in this study. Second, we thank the management and staff of the Psychosomatic Schön-Clinic in Bad Bramstedt, for their support in patient recruitment. Third, the authors thank Charline Peters, Sara Rieper and Elisabeth Weber, for their assistance in recruiting and assessing the participants.

Funding Open Access funding enabled and organized by Projekt DEAL. This research did not receive any specific grant from funding agencies in the public, commercial, or not-for-profit sectors.

\section{Declarations}

Conflict of interest Jakob Fink-Lamotte, Pauline Platter, Christian Stierle, and Cornelia Exner declare that they have no conflict of interest.

Informed Consent The participants were first informed of the details of the study and the test subjects' written consent to participation was obtained.

Human and Animal Rights The study was approved by the local ethics committee of the University of Leipzig (2019.03.05_eb_3) and therefore the research was conducted in accordance with the 1964 Helsinki Declaration.

Open Access This article is licensed under a Creative Commons Attribution 4.0 International License, which permits use, sharing, adaptation, distribution and reproduction in any medium or format, as long as you give appropriate credit to the original author(s) and the source, provide a link to the Creative Commons licence, and indicate if changes were made. The images or other third party material in this article are included in the article's Creative Commons licence, unless indicated otherwise in a credit line to the material. If material is not included in the article's Creative Commons licence and your intended use is not permitted by statutory regulation or exceeds the permitted use, you will need to obtain permission directly from the copyright holder. To view a copy of this licence, visit http://creativecommons.org/licenses/by/4.0/.

\section{References}

American Psychiatric Association. (2013). Diagnostic and statistical manual of mental disorders (DSM-5®). American Psychiatric Publishing.

Armstrong, T., \& Olatunji, B. O. (2017). Pavlovian disgust conditioning as a model for contamination-based OCD: Evidence from an analogue study. Behaviour Research and Therapy, 93, 78-87. https://doi.org/10.1016/j.brat.2017.03.009

Beck, A. T., Steer, R. A., \& Brown, G. (1996). Beck Depression Inventory-II. PsycTESTS dataset. https://doi.org/10.1037/t00742-000

Brainard, D. H. (1997). The psychophysics toolbox. Spatial Vision, 10, 433-436.

Cisler, J. M., Olatunji, B. O., \& Lohr, J. M. (2009). Disgust, fear, and the anxiety disorders: A critical review. Clinical Psychology Review, 29(1), 34-46. https://doi.org/10.1016/j.cpr.2008.09.007

Eichholz, A., Schwartz, C., Meule, A., Heese, J., Neumüller, J., \& Voderholzer, U. (2020). Self-compassion and emotion regulation difficulties in obsessive-compulsive disorder. Clinical Psychology \& Psychotherapy. https://doi.org/10.1002/cpp.2451

Faul, F., Erdfelder, E., Lang, A.-G., \& Buchner, A. (2007). G*Power 3: A flexible statistical power analysis program for the social, behavioral, and biomedical sciences. Behavior Research Methods, $39,175-191$. 
Field, A. (2013). Discovering statistics using IBM SPSS statistics (4th edition). Sage.

Fink, J., \& Exner, C. (2019). Does transcranial direct current stimulation (tDCS) improve disgust regulation through imagery rescripting? Frontiers in Human Neuroscience, 13, 192. https://doi.org/ 10.3389/fnhum.2019.00192

Fink, J., Pflugradt, E., Stierle, C., \& Exner, C. (2018). Changing disgust through imagery rescripting and cognitive reappraisal in contamination-based obsessive-compulsive disorder. Journal of Anxiety Disorders, 54, 36-48. https://doi.org/10.1016/j.janxdis. 2018.01.002

Fink-Lamotte, J., Widmann, A., Fader, J., \& Exner, C. (2020). Interpretation bias and contamination-based obsessive-compulsive symptoms influence emotional intensity related to disgust and fear. PLoS ONE, 15(4), e0232362. https://doi.org/10.1371/journ al.pone. 0232362

Fox, J., \& Weisberg, S. (2019). An $\{R\}$ companion to applied regression, third edition [Computer software]. Sage. Thousand Oaks CA. Retrieved June 6, 2020 from, https://socialsciences.mcmas ter.ca/jfox/Books/Companion/

Gilbert, P. (2013). Compassion focused therapy: Distinctive features. Verlag: Junfermann.

Gilbert, P. (2009). Introducing compassion-focused therapy. Advances in Psychiatric Treatment, 15(3), 199-208. https://doi.org/10.1192/ apt.bp.107.005264

Goetz, A. R., Lee, H.-J., Cougle, J. R., \& Turkel, J. E. (2013). Disgust propensity and sensitivity: Differential relationships with obsessive-compulsive symptoms and behavioral approach task performance. Journal of Obsessive-Compulsive and Related Disorders, 2(4), 412-419. https://doi.org/10.1016/j.jocrd.2013.07.006

Goodman, W. K., Price, L. H., Rasmussen, S. A., Mazure, C., Fleischmann, R. L., Hill, C. L., Heninger, G. R., \& Charney, D. S. (1989). The Yale-Brown Obsessive Compulsive Scale. I. Development, use, and reliability. Archives of General Psychiatry, 46(11), 1006-1011. https://doi.org/10.1001/archpsyc.1989.0181011004 8007

Görgen, S. M., Hiller, W., \& Witthöft, M. (2016). Die spontaneous use of imagery scale (SUIS)-Entwicklung und teststatistische Prüfung einer deutschen adaption. Diagnostica, 62(1), 31-43. https://doi. org/10.1026/0012-1924/a000135

Haberkamp, A., Glombiewski, J. A., Schmidt, F., \& Barke, A. (2017). The DIsgust-RelaTed-Images (DIRTI) database: Validation of a novel standardized set of disgust pictures. Behaviour Research and Therapy, 89, 86-94. https://doi.org/10.1016/j.brat.2016.11. 010

Hand, I., \& Büttner-Westphal, H. (1991). Die Yale-Brown Obsessive Compulsive Scale (Y-BOCS): Ein halbstrukturiertes Interview zur Beurteilung des Schweregrades von Denk- und Handlungszwängen. Verhaltenstherapie, 1(3), 223-225. https://doi.org/10. 1159/000257972

Hautzinger, M., Keller, F., \& Kühner, C. (2006). Beck depressionsinventar (BDI-II). Harcourt Test Services.

Holmes, E. A., Arntz, A., \& Smucker, M. R. (2007). Imagery rescripting in cognitive behaviour therapy: Images, treatment techniques and outcomes. Journal of Behavior Therapy and Experimental Psychiatry, 38(4), 297-305. https://doi.org/10.1016/j.jbtep.2007. 10.007

Hupfeld, J., \& Ruffieux, N. (2011). Validierung einer deutschen version der self-compassion scale (SCS-D). Zeitschrift Für Klinische Psychologie Und Psychotherapie, 40(2), 115-123. https://doi.org/ 10.1026/1616-3443/a000088

Kassambara, A. (2019). rstatix: Pipe-friendly framework for basic statistical tests (Version R package version 0.3.1) [Computer software]. Retrieved June 6, 2020 from, https://CRAN.R-project.org/ package $=$ rstatix
Kleiner, M., Brainard, D. H., \& Pelli, D. G. (2007). What's new in Psychtoolbox-3. Perception, 36, ECVP Abstract Supplement.

Knowles, K. A., Jessup, S. C., \& Olatunji, B. O. (2018). Disgust in anxiety and obsessive-compulsive disorders: Recent findings and future directions. Current Psychiatry Reports, 20(9), 68. https:// doi.org/10.1007/s11920-018-0936-5

Kunze, A. E., Arntz, A., Morina, N., Kindt, M., \& Lancee, J. (2017). Efficacy of imagery rescripting and imaginal exposure for nightmares: A randomized wait-list controlled trial. Behaviour Research and Therapy, 97, 14-25. https://doi.org/10.1016/j.brat. 2017.06.005

Kunze, A. E., Lancee, J., Morina, N., Kindt, M., \& Arntz, A. (2019). Mediators of change in imagery rescripting and imaginal exposure for nightmares: Evidence from a randomized wait-list controlled trial. Behavior Therapy, 50(5), 978-993. https://doi.org/10.1016/j. beth.2019.03.003

Laux, L., Glanzmann, P., Schaffner, P., \& Spielberger, C. D. (1981). Das State-Trait-Anxiety-Inventory (STAI). Hogrefe.

MacBeth, A., \& Gumley, A. (2012). Exploring compassion: A metaanalysis of the association between self-compassion and psychopathology. Clinical Psychology Review, 32(6), 545-552. https:// doi.org/10.1016/j.cpr.2012.06.003

Mathes, B. M., Day, T. N., Wilver, N. L., Redden, S. A., \& Cougle, J. R. (2020). Indices of change in exposure and response prevention for contamination-based OCD. Behaviour Research and Therapy, 133, 103707. https://doi.org/10.1016/j.brat.2020.103707

Mayring, P. (2010). Qualitative Inhaltsanalyse. In P. Mayring (Ed.), Handbuch qualitative Forschung in der Psychologie (pp. 601613). Verlag für Sozialwissenschaften.

McKay, D. (2006). Treating disgust reactions in contamination-based obsessive-compulsive disorder. Journal of Behavior Therapy and Experimental Psychiatry, 37(1), 53-59. https://doi.org/10.1016/j. jbtep.2005.09.005

Neff, K. D. (2003). Self-compassion: An alternative conceptualization of a healthy attitude toward oneself. Self and Identity, 2(2), 85-101. https://doi.org/10.1080/15298860309032

Neff, K. D., \& Germer, C. K. (2013). A pilot study and randomized controlled trial of the mindful self-compassion program. Journal of Clinical Psychology, 69(1), 28-44. https://doi.org/10.1002/jclp. 21923

Olatunji, B. O., Berg, H. E., Cox, R. C., \& Billingsley, A. (2017). The effects of cognitive reappraisal on conditioned disgust in contamination-based OCD: An analogue study. Journal of Anxiety Disorders, 51, 86-93. https://doi.org/10.1016/j.janxdis.2017.06.005

Olatunji, B. O., Berg, H. E., \& Zhao, Z. (2017). Emotion regulation of fear and disgust: Differential effects of reappraisal and suppression. Cognition \& Emotion, 31(2), 403-410. https://doi.org/10. 1080/02699931.2015.1110117

Olatunji, B. O., Tart, C. D., Ciesielski, B. G., McGrath, P. B., \& Smits, J. A. J. (2011). Specificity of disgust vulnerability in the distinction and treatment of OCD. Journal of Psychiatric Research, 45(9), 1236-1242. https://doi.org/10.1016/j.jpsychires.2011.01. 018

Öst, L.-G., Havnen, A., Hansen, B., \& Kvale, G. (2015). Cognitive behavioral treatments of obsessive-compulsive disorder. A systematic review and meta-analysis of studies published 1993-2014. Clinical Psychology Review, 40, 156-169. https://doi.org/10. 1016/j.cpr.2015.06.003

R Core Team (2021). $R$ : A language and environment for statistical computing. R Foundation for Statistical Computing, Vienna, Austria. https://www.R-project.org/.

Reisberg, D., Pearson, D. G., \& Kosslyn, S. M. (2003). Intuitions and introspections about imagery: The role of imagery experience in shaping an investigator's theoretical views. Applied Cognitive Psychology, 17(2), 147-160. https://doi.org/10.1002/acp.858 
Salkovskis, P. M. (1999). Understanding and treating obsessive-compulsive disorder. Behaviour Research and Therapy, 37, S29-S52. https://doi.org/10.1016/S0005-7967(99)00049-2

Schienle, A., Zorjan, S., \& Wabnegger, A. (2020). A brief measure of disgust propensity. Current Psychology. https://doi.org/10.1007/ s12144-020-00883-1

Schienle, A., Schäfer, A., Stark, R., Walter, B., \& Vaitl, D. (2005). Gender differences in the processing of disgust- and fear-inducing pictures: An fMRI study. NeuroReport, 16(5), 277-280.

Schienle, A., Walter, B., Stark, R., \& Vaitl, D. (2002). Ein Fragebogen zur Erfassung der Ekelempfindlichkeit (FEE). Zeitschrift Für Klinische Psychologie Und Psychotherapie, 31(2), 110-120. https:// doi.org/10.1026/0084-5345.31.2.110

Schmucker, M., \& Köster, R. (2015). Narrative um-schreibung: Imagery rescripting \& reprocessing therapy (IRRT). In M. Linden \& M. Hautzinger (Eds.), Verhaltenstherapiemanual Psychotherapie. Praxis.

Siegesleitner, M., Strohm, M., Wittekind, C. E., Ehring, T., \& Kunze, A. E. (2019). Effects of imagery rescripting on consolidated memories of an aversive film. Journal of Behavior Therapy and Experimental Psychiatry, 62, 22-29. https://doi.org/10.1016/j. jbtep.2018.08.007

Sommers-Spijkerman, M. P. J., Trompetter, H. R., Schreurs, K. M. G., \& Bohlmeijer, E. T. (2018). Compassion-focused therapy as guided self-help for enhancing public mental health: A randomized controlled trial. Journal of Consulting and Clinical Psychology, 86(2), 101-115. https://doi.org/10.1037/ccp0000268

The MathWorks Inc. (2019). MATLAB (Version version 9.7.0.1247435) [Computer software].

Wild, J., Hackmann, A., \& Clark, D. M. (2008). Rescripting early memories linked to negative images in social phobia: A pilot study. Behavior Therapy, 39(1), 47-56. https://doi.org/10.1016/j. beth.2007.04.003

Wittchen, H.-U., Zaudig, M., \& Fydrich, T. (1997). SKID. Hogrefe.

Publisher's Note Springer Nature remains neutral with regard to jurisdictional claims in published maps and institutional affiliations. 